\title{
Load Sharing Characteristic of Single Phase PV Inverter Connected to Grid
}

\author{
M. Imran Hamid*, Makbul Anwari* Member, IEEE, Z. Salam* Member, IEEE, and \\ Taufik**, Senior Member, IEEE. \\ * Department of Energy Conversion Engineering, Faculty of Electrical Engineering, \\ Universiti Teknologi Malaysia, Johor Bahru, Malaysia, Email: imrandgmasse@yahoo.com \\ **Cal Poly State University, San Luis Obispo, CA 93407, USA.
}

\begin{abstract}
This paper describes model and simulation of single phase PV inverters that work independently to supply three phase system as a part of renewable distributed generation. Load sharing characteristic of PV inverter and grid during supplying local load with current control method and relation of $P V$ power level and current control performance to load sharing are simulated and analyzed. Furthermore, power quality behavior during connection/disconnection of PV plant, grid harmonics, voltage and current unbalance are simulated and analyzed. Model and simulation are implemented using MATLAB/Simulink.
\end{abstract}

Keywords--- Single phase PV inverter, current controller

\section{INTRODUCTION}

Application of photovoltaic as electrical energy source shows increasing trend both in implementation on spread area over the world and in capacity of plant. This trend is triggered by many factors such as the increasing of fossil fuel cost and declination of production cost per $\mathrm{kW}$ electric from photovoltaic and also technology development that cause the photovoltaic power conversion more efficient [1].

Photovoltaic generation system can either be operated in isolated system or be connected to the grid to form integrated system, and with other electrical renewable energy source can form distributed renewable energy generation. In an integrated photovoltaic generation, one among aspects that take attention of researches is the power flow and load sharing problem between the grid and photovoltaic plant in order to supply electrical power for connected load, it is intended that power flow mechanism ensure that energy generated by the plant can be sent to the grid optimally. In such a system, load flow and load sharing mechanism are handled by the inverter as power interface between plant and grid, by using appropriate method, intended power flow and load sharing control can be achieved.

Other aspect concerning to application of photovoltaic as a part of distributed generation is the power quality resulted from their operation, especially for voltage unbalance and harmonics. Trend application of some single phase PV inverters and its PV array connected together to supply three phase system as alteration of high capacity centralized three phase PV inverter can be a factor that effect to unbalance grid voltage due to diversity of irradiance among array [2,3]. Harmonics distortion as a result of interaction between PV inverter and other part of the grid components is also one aspect that continuing explored [4].

This paper describes model and simulation of several single phase PV inverters that work independently to supply three phase system. Model and simulation of load flow and load sharing control between PV generation will be presented. The current of PWM voltage source PV inverter is controlled by current control strategy (CCVSIPWM) using grid parameter as current reference [5] and then implement to ramp comparison and hysteresis control method. Further, effect of irradiance level and current control performance to load flow and load sharing will be analyzed. Power quality aspect due to unbalance supply between single phase PV inverter and grid power quality behavior is also simulated and evaluated. Model and simulation are implemented using MATLAB/Simulink

\section{PV MODULE-INVERTER CONFIGURATION}

In PV generation system, PV inverter hold the role as interface between photovoltaic module and ac power grid. In this function, PV inverter and associated generation system equipment should have ability to maximize power extracting from the array, match DC voltage output from PV array, produce sinusoidal ac voltage with minimum distortion on output side, and control the power flow. If the PV inverter is from grid tie type, it must be completed with synchronizing mechanism and protection system from islanding condition or from others negative impact of grid phenomena. In certain application, there are also need for data communication and monitoring, nowadays many commercial PV inverters have completed by advance data communication and monitoring system facilities.

From overall basic abilities listed above, PV inverter is hoped to operate in optimum conversion efficiency. Photovoltaic material exploration, converter topologies and its control mechanism have and being continuously 
developed. Development of effective conversion is can also be reached by optimizing configuration between PV module/array and associated PV inverter. In application, according to connection and configuration between PV module and PV inverter, photovoltaic generation plant can be identified as:

\section{a. Photovoltaic generation using central PV inverter}

This configuration is reached by paralleling some PV module strings (some PV modules in serial connection) and connected to dc side of a relatively large capacity PV inverter. High conversion efficiency can be reached from this configuration but faces weakness if there are diversity of PV module and diversity of irradiance or partial shading. This configuration is also susceptible to reliability problem because whole PV generation plant depend on only one equipment. This configuration is often implemented on high capacity generation plant to optimize the cost, but unfortunately this is also a drawback because it is limiting the flexibility to adjust plant capacity.

\section{b. Photovoltaic generation using string PV inverter}

To overcome the weakness of central inverter configuration, the string PV inverter configuration was introduced. In this topology, each PV module string is connected to its PV inverter with own MPPT respectively. By this way, optimum power extracting from each string can be achieved, overall efficiency is better and PV generation reliability is increased because the system does not depend to only one equipment anymore. Plant capacity is also easy to adjust to follow demand dynamic.

\section{c. Photovoltaic generation using multi-string $P V$ inverter}

This configuration is developed to adopt the cost and technical advantageous of both previous configurations. Some PV module strings with dc-dc converter and their own MPPT mechanism are connected to a PV inverter. Optimum power extracting from each module string can be achieved and in other side reduced cost for dc-ac converter can be done.

\section{d. Photovoltaic generation using team system}

Even though optimum power extraction can be achieved using multi-string PV inverter configuration, but implementation of a single dc-ac converter on second stage of electrical conversion in other hand decreasing the reliability of generation system. Team system configuration was introduced to solve this problem, this configuration contains several PV module strings and its own PV inverters set in parallel. When irradiance high enough, each PV module strings and its own PV inverters work independently to supply power for ac side, on the contrary, if the irradiance go down, module string configuration is changed in such a way so that not all of dc-ac converter operate. This scheme ensures that dc-ac converter always operates around their rated power.

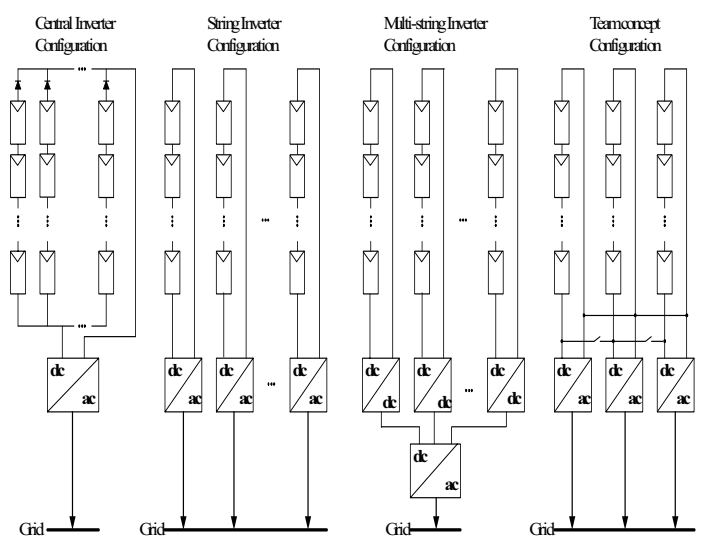

Figure 1. Some PV module configurations in a PV plant $[3,6]$

The above configuration of $\mathrm{PV}$ generation systems is described on Fig.1. String PV inverter, influenced by cost consideration, plant capacity, and flexibility to enlarge the plant have shown wide implementation and have evolved to become standard PV system technology for grid connected PV generation plant [6]. String PV inverter for capacity under $5 \mathrm{~kW}$ generally produced in single phase, to form three phase supply to the grid it is done by connecting at least three inverters, by this system, flexibility to adjust plant capacity is easier.

\section{LOAD SHARING METHOD OF PV INVERTER}

Load flow control in PV generation is done by power converter using appropriate load flow control method. In this case, current control and voltage control method are widely used. Voltage control method uses error of grid voltage and distributed generation terminal voltage on both side of coupling inductor as control signal for the controller, meanwhile current control method uses error between actual current sent and desired (setting) current as control signal [5].

Current control method has some advantageous compared to voltage control method that cause this method is preferred to use in many converter application [7]. In current control method, to determine switching instant, two, out of many strategies can be used: hysteresis and ramp time comparison current control. Here the two methods describe as follows [8]:

\section{a. Hysteresis current control}

In this method, inverter output current is forced to follow the current reference. Deviation between these two quantities is limited by upper and lower band in a hysteresis loop. If actual current reach upper limit of hysteresis band, the inverter leg is switched off so that the current decrease till reach lower band of hysteresis loop. In this point, the inverter leg is switch on again and actual current back to increase to upper band, the process repeat continuously. The sinusoidal-wave shape of reference signal causes inverter switching frequency vary 
and gives different current ripple in one fundamental inverter period. Gap width between upper and lower band of hysteresis loop determine the magnitude of current ripple. The hysteresis control method and inverter current shape is shown in Fig. 2.

\section{b. Ramp comparison current control}

In this mode of controller, a sinusoidal-wave signal is added to a triangle signal for creating a sinusoidaltriangle reference. This reference then compare with actual current. The point where sinusoidal - triangle wave and actual current crosses become time when the inverter leg is switched. If the current error greater than sinusoidal-triangle, the inverter leg is switch off and in contrary if the current error less than sinusoidal-triangle then the inverter leg is switch on. As the hysteresis methods, this method also causes the inverter switching frequency and PWM pulse width vary and give different current ripple in one fundamental inverter period. The Ramp comparison current control method and inverter current shape created are shown in Fig.3.
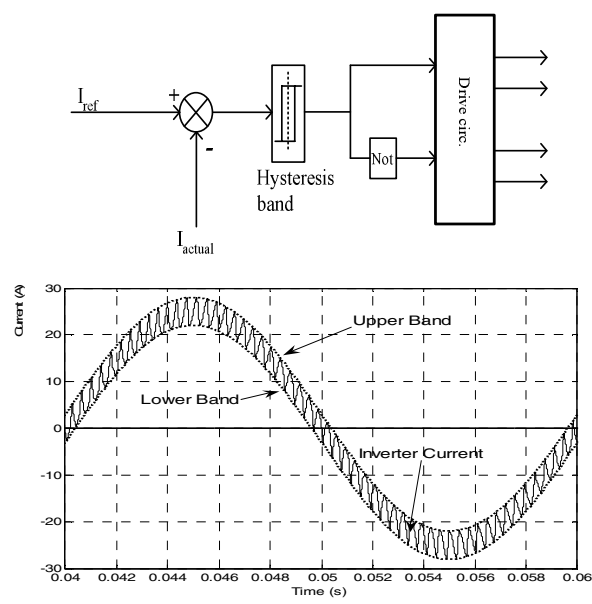

Figure 2. Hysteresis controller
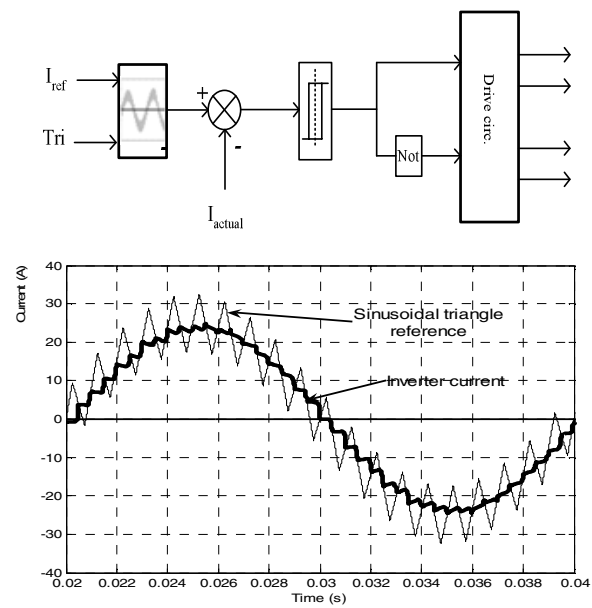

Figure 3. Ramp comparison controller

\section{LOAD FLOW AND LOAD SHARING CHARACTERISTIC OF PV INVERTER}

Fig. 4 shows simplified simulation circuit diagram to show load flow characteristic of several single phase inverters connected to grid. Photovoltaic dc power is generated from $\mathrm{PV}$ array with variable input temperature and irradiance, PV inverter then convert dc to ac voltage with frequency and phase according to detected grid voltage using phase locked loop (PLL) scheme [9]. Power flow to grid is controlled by current controller based on current reference set up, two current control methods described previously are implemented. The simulation then run to show voltage and current of the grid during PV generation plant is switch on and switch off. Electric motor is also added to observe the system respond due to dynamic load operation.

Fig.5 and 6 shows application of both current control method described above that use to control PV inverter current. For 10 Amp setting current sent to the grid, hysteresis control cause distortion to the line parameter of $3.35 \%$ THD for voltage distortion and $9.58 \%$ THD for current distortion, more ripple appear both on line voltage and current during PV inverters are switch on. In the other hand, ramp comparison control method gives less distortion both line voltage and current. For the same sent current set up, this control method gives 0.44 THD for voltage distortion and $1.25 \%$ THD for current distortion. Higher distortions appear on inverter switching event.

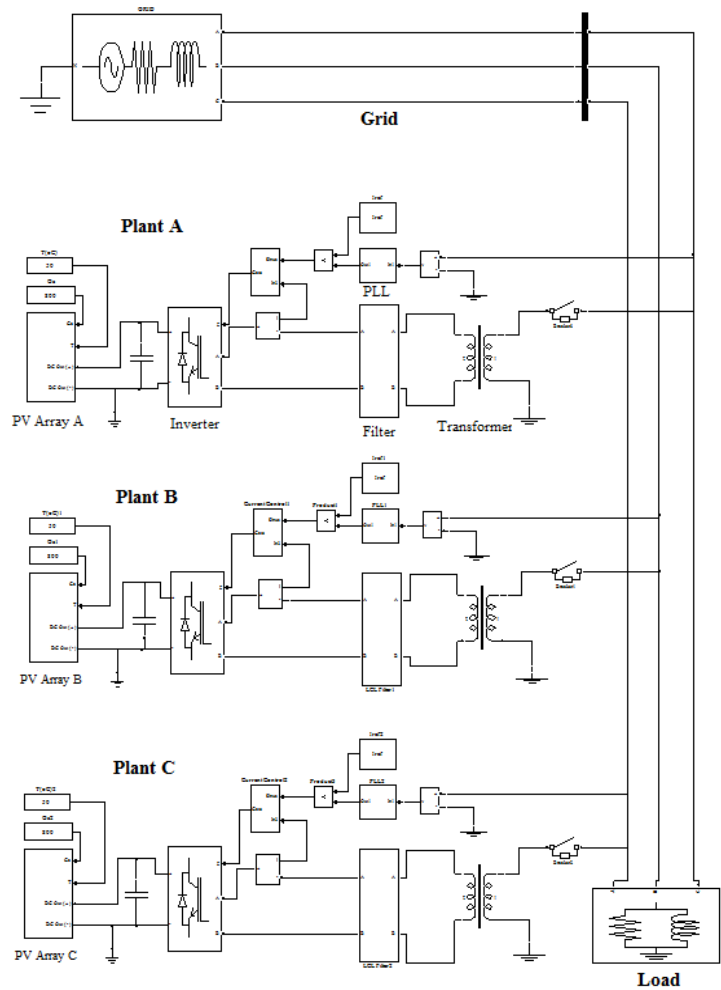

Figure 4. Three single phase inverters are connected to grid 
The current drawn by connected load is supplied from both grid and PV plant. It is different with paralleling two sources such as transformers or generators in supplying a connected load, where capacity and internal impedance are parameter that determine load sharing between both equipments, load current drawn by PV inverter in a grid is not depend on capacity of PV plant. Optimum power can be sent to grid as long as there are sufficient power generated by the plant. Fig. 7 shows simulation result on how a certain load current is supplied from both grid and PV inverter. Initially, whole load drawn by constant load is supplied from the grid, at point when PV plant switch on, PV plant current increase meanwhile the current from grid decrease and then go to steady condition till the PV plant switch off. A switching surge appears as distortion during switch on.
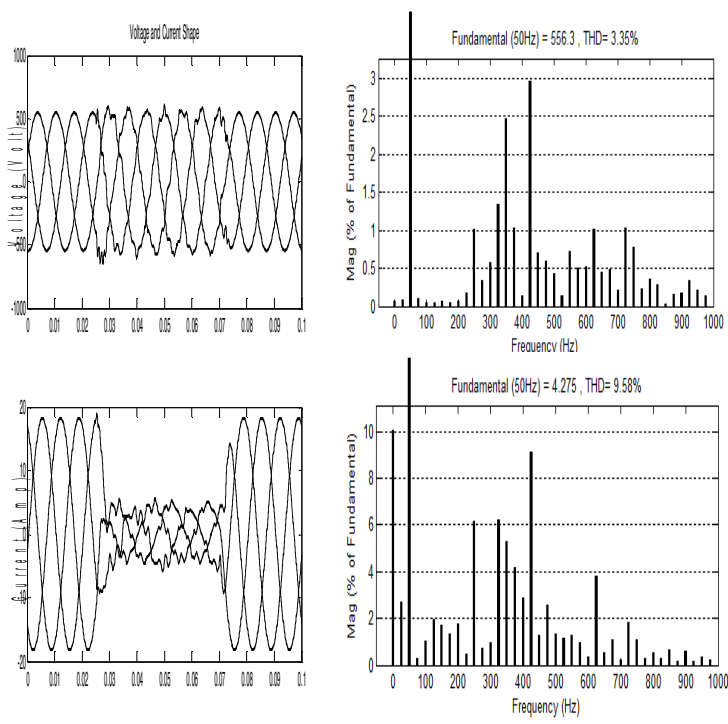

Figure 5. Grid voltage and current when PV inverters are controlled using hysteresis control method
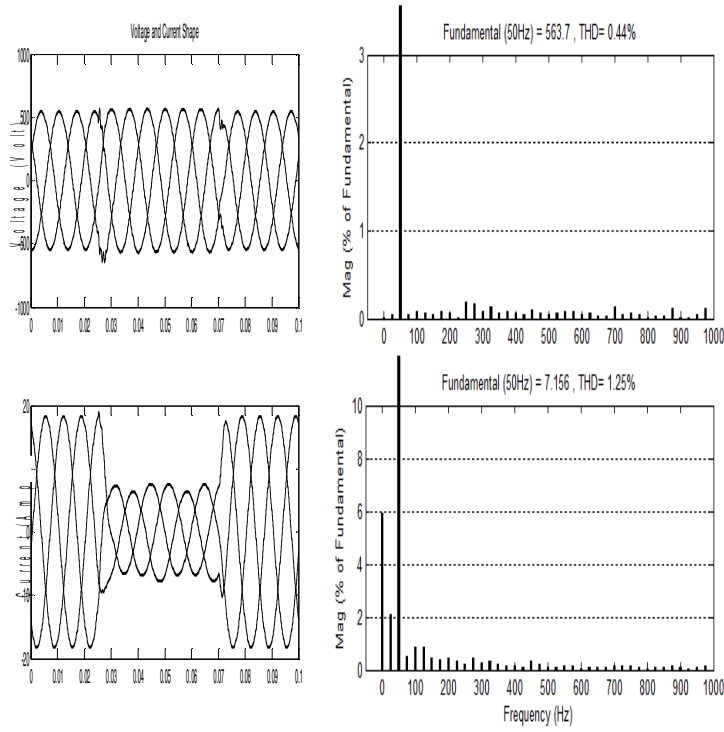

Figure 6. Grid voltage and current when PV inverters are controlled using ramp comparison control method

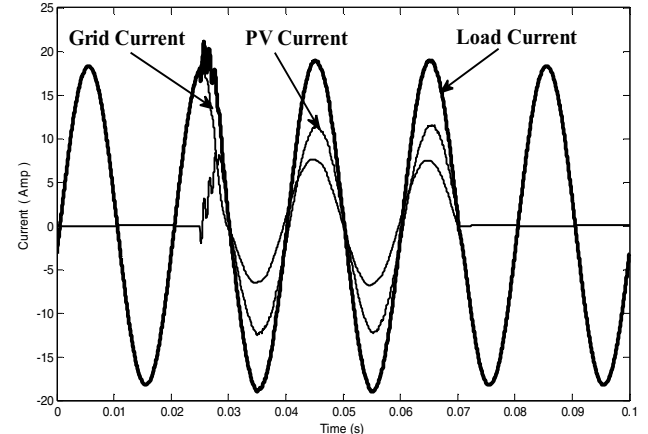

Figure 7. Load current sharing between grid and plant on phase $a$ when PV plant is switched

Grid parameter condition when an ASD of induction motor as dynamic load is shown in Fig. 8. Initially in time range $t_{1}$, a resistive load have already connected and supplied fully by the grid. At the beginning of $t_{2}$, all single phase PV inverters are switch on simultaneously so that resistive load current is supplied from both the grid and PV plant. Further, at the beginning of $t_{3}$ the motor is switch on so that current from grid and PV plant flows to the motor. High current appear during starting period, the current then decrease along with increasing of motor speed and tend to stable when the motor reaches its nominal speed. Harmonics distortion on input line voltage caused by power converter in motor ASD is also appear.

Current sharing during starting condition shows that the grid supply more and dominant current for the motor than PV plant, but on the contrary in the steady state condition more current flow from PV plant. This phenomena can be explain as follow: during starting, cause of line impedance, the grid voltage experiences voltage drop. Because PLL in PV inverter operates based on grid voltage, which its reference current for current control follows the grid voltage shape, so that during grid voltage drop, the current created by PV inverter also drop and imitate the grid voltage shape, high starting current automatically compensated by the grid. More current flows from the grid. On the steady state condition which line voltage drop have vanished, the current from PV plant back to normal shape as current set up of PV inverter.

In a PV plant that use a number of single phase PV inverter, unbalance supply between phase is un avoided. Unbalance supply may be resulted from diversity of irradiance between PV array or partial shading in a part of PV array. Variation of irradiance cause the operation point of PV inverter's MPPT is shifted to different level of current output on V-I characteristic of the array. In load flow control mechanism of PV inverter, variation of irradiance is responded by adjusting the current reference of the current control. Because of each PV inverter works independently, then current level sent by each PV inverter to three phase grid are different. 

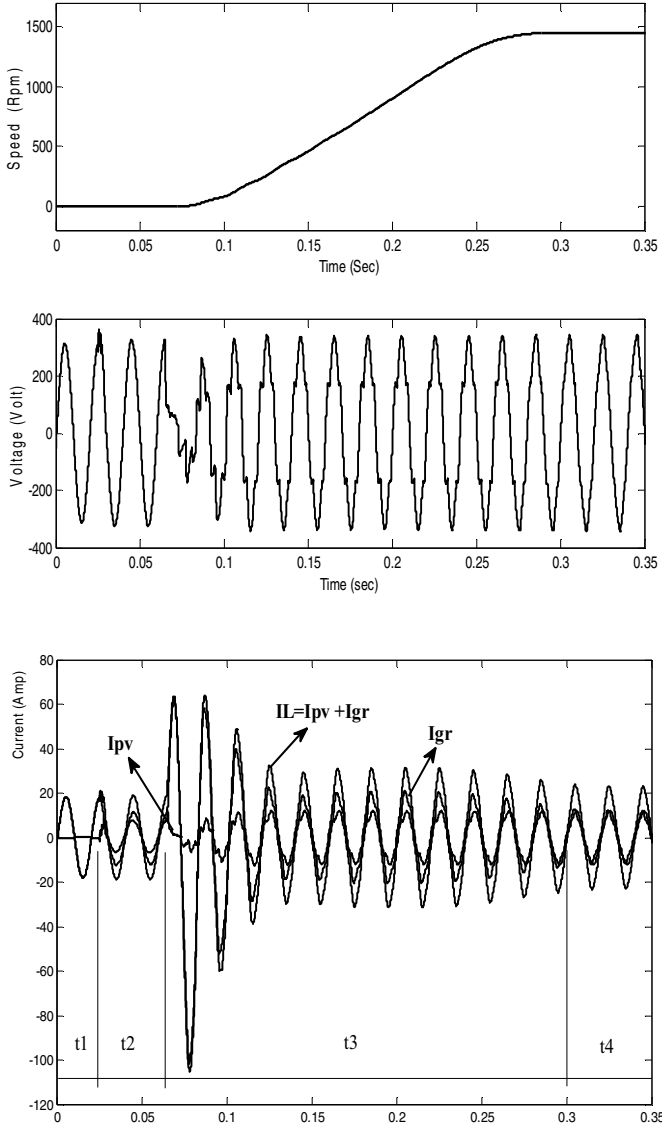

Figure 8. Motor speed, grid voltage and current sharing between grid and PV plant on phase $a$ when motor is switched on

\section{CONCLUSION}

Simulation result based on MATLAB/Simulink of several single phase PV inverters that work independently to supply three phase system was presented. Load sharing characteristic between PV inverters and grid using two current control method show that the ramp time comparison control gives lower power distortion than hysteresis current control. Simulation also shown that in synchronizing and connecting PV inverter to grid, application of grid voltage as PLL reference is disadvantageous when the grid voltage is distorted as the grid operates with dynamic and non linear loads.

\section{ACKNOWLEDGMENT}

The authors thank the Malaysian Government, Ministry of Science, Technology and Innovation (MOSTI) and Universiti Teknologi Malaysia for the E-Science Fund Grant, Vot. No. 79140.

\section{REFERENCES}

[1] Trends in Photovoltaic Applications. Survey Report of Selected IEA Countries Between 1992 and 2006. International Energy Agency Photovoltaic Power Systems, IEA-PVPS-T1-16:2007. [Online]. Available: www.iea-pvps.org

[2] P.A.B. James, A.S. Bahaj, R.M. Braid, "PV array $<5 \mathrm{kWp}+$ single inverter $=$ grid connected $\mathrm{PV}$ system: Are multiple inverter alternatives economic?", Solar Energy 80 (2006) 1179-1188

[3] M. Calais, J.M.A. Myrzik, T. Spooner, V.G. Agelidis, "Inverters for Single-Phase Grid connected Photovoltaic - An overview," Power Electronics Specialists Conference, vol 2, page 11731178, 18-23 June 2001, Bologna Italy.

[4] J.H.R. Enslin, Peter J. M. Heskes, "Harmonic Interaction Between a Large Number of Distributed Power Inverters and the Distribution Network," IEEE Trans. On Power Electronics, vol. 19, no. 6, November 2004.

[5] S. H. Ko, S. R. Lee, and H. Dehbonei, "Application of Voltageand Current-Controlled Voltage Source Inverters for Distributed Generation System," IEEE Trans. Energy Conversion, vol. 21, no. 3, pp. 782-792, September 2006.

[6] F. Blaabjerg, R. Teodorescu, Z. Chen and M. Liserre, "Power converter and control of renewable energy systems"

[7] L. Borle, M. Dymond, and C.V. Nayar, "Development and testing of a $20 \mathrm{~kW}$ grid interactive photovoltaic power conditioning system in Western Australia", 1996.

[8] D. M. Brod and D. W. Novotny, "Current Control of VSI-PWM Inverters," IEEE Trans. on Industry App. vol. IA-21. no. 4 , May/Jun 1985.

[9] Ciobotaru, M., Teodorescu, R., and Blaabjerg, F., "A New Single-Phase PLL Structure Based on Second Order Generalized Integrator," Power Electronics Specialists Conference, 2006. PESC '06. 37th IEEE, vol., no., pp. 1-6, 18-22 June 2006 